OPEN ACCESS

Edited by:

Pascal Brault,

Centre National de la Recherche Scientifique (CNRS), France

Reviewed by:

Eugen Stamate,

Technical University of Denmark,

Denmark

Herbert Gunell,

Belgian Institute for Space Aeronomy,

Belgium

${ }^{*}$ Correspondence:

Filip Moens

filip.moens@ugent.be

Diederik Depla

diederik.depla@ugent.be

Specialty section:

This article was submitted to

Plasma Physics,

a section of the journal

Frontiers in Physics

Received: 17 August 2017 Accepted: 03 October 2017 Published: 18 October 2017

Citation:

Moens $F$, Konstantinidis $S$ and Depla D (2017) The Target Material Influence on the Current Pulse during High Power Pulsed Magnetron Sputtering. Front. Phys. 5:51. doi: 10.3389/fphy.2017.00051

\section{The Target Material Influence on the Current Pulse during High Power Pulsed Magnetron Sputtering}

\author{
Filip Moens $^{1 *}$, Stéphanos Konstantinidis ${ }^{2}$ and Diederik Depla ${ }^{1 *}$ \\ ${ }^{1}$ Department of Solid State Sciences, Ghent University, Ghent, Belgium, ${ }^{2}$ Chimie des Interactions Plasma-Surface, Université \\ de Mons, Mons, Belgium
}

The current-time characteristic during high power pulsed magnetron sputtering is measured under identical conditions for seventeen different target materials. Based on physical processes such as gas rarefaction, ion-induced electron emission, and electron impact ionization, two test parameters were derived that significantly correlate with specific features of the current-time characteristic: (i) the peak current is correlated to the momentum transfer between the sputtered material and the argon gas, (ii) while the observed current plateau after the peak is connected to the metal ionization rate.

Keywords: HPPMS, gas rarefaction, electron emission, target material, waveform analysis

\section{INTRODUCTION}

From a curiosity within the coating technology [1], high power pulsed magnetron sputtering (HPPMS) has rapidly become a well-established deposition technique with a broad application field. A full review of these applications would be out of the scope of this paper, so only a few examples will be given. The usage of HPPMS has been demonstrated for different applications such as hard coatings [2-4], optical thin films [5-7], electrical applications [8-10], catalysis [1113], adhesive and/or low friction coatings [14, 15], anti-bacterial thin films [16], and conformal coatings [17]. The technique has introduced also some interesting new insight in terms of plasma physics which are presented in a large number of scientific papers, and summarized in a few highly cited reviews [5, 18-20]. The intricate dynamics is transcribed by the current waveform which has been studied in several ways. An overall understanding of the discharge current behavior has now been reached. Processes such as gas rarefaction, self-sputtering, electron emission by single and multi-charged species, and electron impact ionization come into play to define the current waveform. An overview of possible current waveforms has been presented by $\mathrm{Wu}$ et al. [21]. As commonly known, the mentioned processes depend strongly on the target material. Nevertheless, only a limited number of papers has studied the impact of the target material on the current waveform [22]. Moreover, a literature search reveals that only a limited number of materials are actually studied. The literature study was performed by using the combination of the keywords (HPPMS or HIPIMS) and (element) in the Web of Science. Indeed, more than half of the papers (397 out of the 727) deal with $\mathrm{Ti}, \mathrm{Al}$ and/or Cr. Rather arbitrarily we define "a well-studied material" as a material with $10 \%$ of the number of papers of the most studied material, i.e. titanium. From this definition only six elements $(\mathrm{Ti}, \mathrm{Al}, \mathrm{Cr}, \mathrm{Si}, \mathrm{Cu}$, and $\mathrm{Nb}$ ) can be given this label. The wide variety in experimental conditions makes comparison difficult. Therefore, in this paper we have studied the current waveform for 17 different target materials under identical conditions. The selection has been made based on metals studied to some extend in literature [ $\mathrm{Ti}, \mathrm{Al}, \mathrm{Cr}, \mathrm{Cu}, \mathrm{Nb}, \mathrm{Zn}, \mathrm{V}, \mathrm{Ag}, \mathrm{Ta}$, $\mathrm{Zr}$, and $\mathrm{Y}$, with exception of $\mathrm{Si}$ (semiconductor), and $\mathrm{Fe}$ (magnetic)] together with some less studied 
materials (Mo and $\mathrm{Mg}$ ), and three new materials ( $\mathrm{Pb}, \mathrm{Sm}$, and $\mathrm{Nd}$ ). The requirement to obtain the current waveform for identical conditions sometimes prevent to reach typical HPPMS conditions, but as will be discussed further this has no dramatic effect on the studied correlations. To make some reasoning more clear specific experiments were performed with $\mathrm{Mg}$.

\section{MATERIALS AND METHODS}

The experiments were performed in a cubic $\left(0.5 \times 0.5 \times 0.5 \mathrm{~m}^{3}\right)$ stainless steel vacuum chamber pumped by a combination of a turbomolecular pump and a rotary vane pump to a base pressure of less than $5 \times 10^{-4} \mathrm{~Pa}$ as measured with a Penning gauge. Two inch targets (Testbourne and K.J. Lesker with a purity higher than $99.5 \%$ ) were mounted on a home-made circular planar magnetron. Before the HPPMS experiments, the target was sputter cleaned in DC mode until a constant discharge current was registered. The HPPMS experiments were performed in pure argon at a pressure of $1.8 \mathrm{~Pa}$, obtained by an argon flow of $70 \mathrm{sccm}$ (standard cubic centimeter per minute) as measured with a capacitance gauge. The magnetron was powered with a Melec SIPP2000 power supply. A ferrite ring, and cable twisting, were used to reduce any electromagnetic interference. The voltage probe was a Tektronix P1500A (bandwidth $500 \mathrm{MHz}$ ).

To measure the discharge current, a TCPA300 current transducer was used in combination with a TCP3030 current probe (bandwidth $15 \mathrm{MHz}$ ). The voltage and current were recorded with a DSO1024A (bandwidth $200 \mathrm{MHz}$ ) oscilloscope. An overview of the experimental set-up is schematically depicted in Figure 1. All experiments were performed by applying a $500 \mathrm{~V}$ voltage pulse with a pulse length of $400 \mu \mathrm{s}$, and a duty cycle of $10 \%$. These settings were chosen, together with the argon pressure, to allow a stable plasma for all elements under identical conditions. Additional experiments as a function of the erosion groove depth were performed with magnesium. To avoid any effects of target contamination and/or misalignment between the target and the magnet assembly, the target was not removed from the vacuum chamber to measure the erosion depth. To access the erosion depth, the linear correlation between the erosion groove depth and the discharge voltage (obtained during DCMS) observed during previous work $[23,24]$ was used. For different erosion depths of the target, I-V characteristics were measured by changing the applied voltage. Also the deposition rate was determined. The latter was obtained by dividing the measured thickness of deposited $\mathrm{Mg}$ films by the deposition time. The film thickness was measured by profilometry (TaylorHobson, Talystep). One of the derived correlations (see section 3.3) is based on the collision between the sputtered atoms with the working gas atoms. To affect the discharge properties these collisions need to take place close to the target. To calculate the average transferred energy per sputtered atom $E_{\text {trans }}$, particle trajectory Monte Carlo simulations were performed using the SIMTRA code [25, 26]. The experimental set-up (see Figure 1) was implemented, and for each target material 2,000 test particles were launched from the target. The test particles were randomly selected from a Thompson energy distribution, and a cosine angular distribution. The number of collisions within a cylindrical volume defined by the target radius $(2.54 \mathrm{~cm})$ and a height of $2.5 \mathrm{~cm}$ was calculated. The choice of the volume is rather arbitrarily, but it is expected that the energy transfer within this volume will affect the discharge properties. A similar assumption was made by Raadu et al. [27] in the derivation of the ionization region model for HPPMS.

\section{RESULTS AND DISCUSSION}

\subsection{Experiments with Magnesium}

I-V characteristics of magnetron discharge are commonly presented on a log-log plot as the I-V characteristic can be empirically described as $I=k V^{n}$. In the case of HPPMS its quite common to plot the peak current as a function of the discharge voltage. A linear fit through the data points permits in this way to determine the value of $n$ which expresses the I-V characteristic steepness and reflects the ionization efficiency in the considered working conditions. To illustrate the impact of the steepness on the overall waveform measured during HPPMS, magnesium targets were sputter eroded. The influence of the target erosion groove depth can be understood from the increase of the magnetic field strength when the target becomes more eroded. At sufficient high pressure, the increased magnetic field strength generally results in an increase of the steepness [28]. This behavior was shown for HPPMS by Čapek et al. by increasing the target-to-magnet distance with paramagnetic $\mathrm{Cu}$ spacers $[29,30]$. Magnesium has one of the highest sputtering yield as compared to other metals in this study. This permits to erode the target in a relative short time, and study the effect of target erosion on the HPPMS waveform and the I-V characteristic of the discharge. Figure 2 shows the change of the current waveform as a function of the target erosion depth. A clear peak is followed by stable plateau irrespective of the erosion groove depth. The figure shows also an analysis of the peak current and the plateau current. Both strongly increase in a similar fashion with the erosion groove depth. The ratio between both (not shown) remains more or less constant. The I-V characteristics for the same erosion depths were measured by increasing the applied voltage between $300 \mathrm{~V}$ and $650 \mathrm{~V}$.

The steepness of the slope $\mathrm{n}$ is shown as function of the erosion depth in the top left panel of Figure 2. An increase of the steepness is observed. It is clear that with increasing erosion groove depth both the peak current, the plateau current, and the steepness of the I-V characteristic increase. The right top panel shows the deposition rate as a function of the erosion groove depth. A linear correlation (correlation coefficient 0.9725 for 8 data points) is observed.

\subsection{Material Dependency}

Figure 3 shows the measured current (I-t) (red traces), and the voltage-time $(\mathrm{V}-\mathrm{t})$ pulse (blue traces) for the 17 different target materials. The effective discharge voltage for all materials lies between 482 and $504 \mathrm{~V}$, but no systematic trends between the used target material and the average discharge voltage within the pulse were noticed. A well-defined rectangular voltage is observed, except for $\mathrm{Ag}, \mathrm{Cu}, \mathrm{Pb}, \mathrm{W}$, and $\mathrm{Zn}$. For these latter 


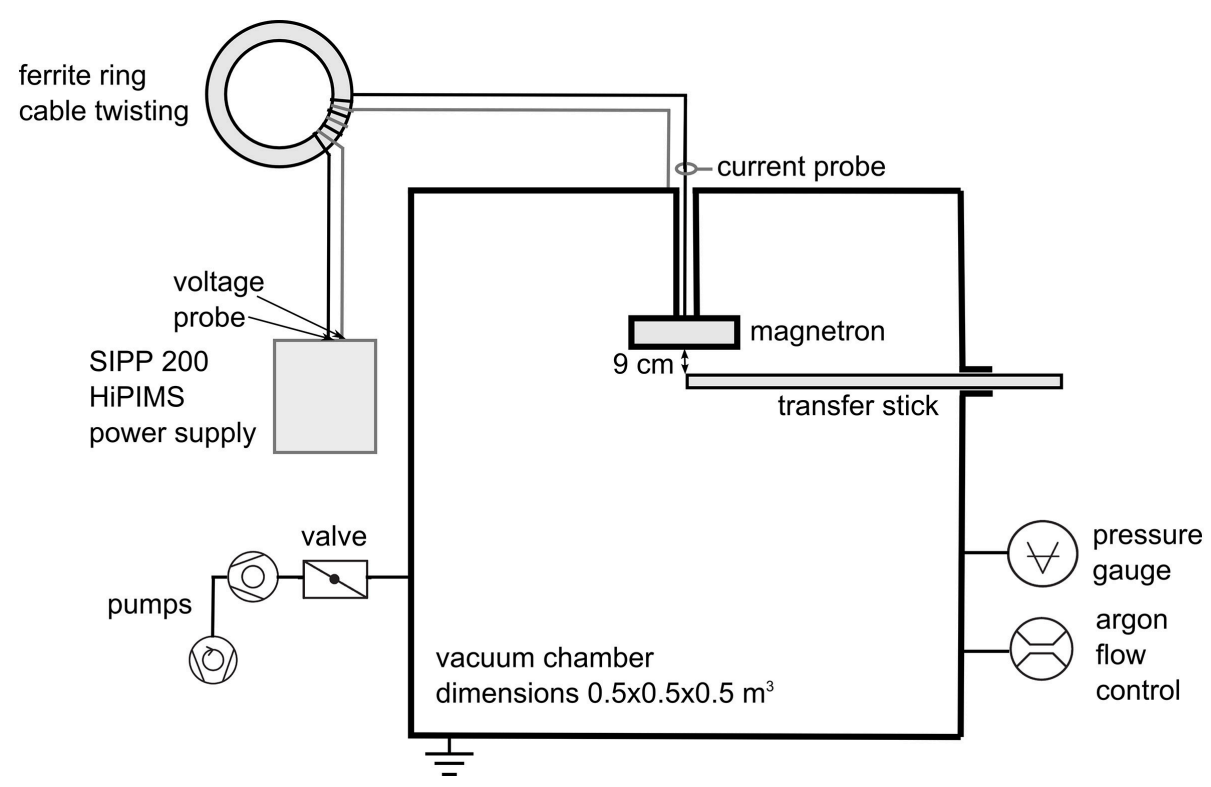

FIGURE 1 | Schematic overview of the experimental set-up. The stainless vacuum chamber is pumped by a combination of a turbomolecular pump combined with a rotary vane pump. The planar cylindrical magnetron is powered by a HiPIMS power supply. A ferrite ring, and cable twisting, were used to reduce any electromagnetic interference. The voltage probe was a Tektronix P1500A (bandwidth $500 \mathrm{MHz}$ ). To measure the discharge current, a TCPA300 current transducer was used in combination with a TCP3030 current probe (bandwidth $15 \mathrm{MHz}$ ). The voltage and current were recorded with a DSO1024A (bandwidth $200 \mathrm{MHz}$ ) oscilloscope. Depositions were performed on silicon substrates introduced in the vacuum chamber through a load lock.

elements, a transient regime toward $0 \mathrm{~V}$ is noticed when the discharge voltage is switched off. This behavior is probably related to the higher plasma impedance for these target materials which hinders the charge removal in the pulse-off time. This point is inspired by the fact that exactly for these five materials the effect of gas rarefaction is the strongest (see further, Figure 4).

A clear difference can be noticed in both peak current and the overall behavior of the discharge current as a function of time between the different materials. Nevertheless, all current waveforms have a similar shape fitting to mode $V$ as presented in the paper of $\mathrm{Wu}$ et al. [21], i.e. a clear peak followed by a stable plateau current. For $\mathrm{Nd}$ and $\mathrm{Sm}$, the peak is less defined, and one could also argue that the shape fits to mode III. Important for the following discussion is that for some materials $(\mathrm{Ag}, \mathrm{Cu}$, and $\mathrm{Zn}$ ) the selected settings do not result in a HPPMS discharge according to the classification by Gudmundson et al. [31]. For all other materials the peak power density is well above the defined threshold of $0.05 \mathrm{~kW} . \mathrm{cm}^{-2}$ for direct current magnetron sputtering (DCMS) and ranges between $0.1 \mathrm{~kW} . \mathrm{cm}^{-2}(\mathrm{~W})$ and $0.6 \mathrm{~kW} . \mathrm{cm}^{-2}(\mathrm{Nb})$. Statistically significant correlations between on the one hand some characteristics such as peak current and plateau current, and on the other hand material properties were systematically investigated. The results are discussed in the following subsections.

\subsection{Peak Current}

The presence of a peak in the I-t diagram has been discussed in the literature. The main reason is the rarefaction of the working gas due to momentum transfer between the sputtered atoms, and working gas atoms. This reasoning is substantiated by experimental evidences based on different plasma diagnostic techniques [32]. However, modeling also indicates there is an alternative mechanism for gas rarefaction, i.e. ionization losses [33]. Although the authors of the latter paper conclude that the sputter wind contribution would become more important at higher pressure. From a more conceptual viewpoint, the above reasoning regarding gas rarefaction can easily be tested. On the one hand, the applied voltage will, similarly to DCMS, result in a current increase defined by the discharge impedance. Indeed, as illustrated with the magnesium experiments, the peak current increases if the discharge is run in a condition for which ionization is more efficient. The latter can be explained from an increased effective secondary electron emission. The electrons are trapped closer to the target for a stronger magnetic field. This results in more ionization within the sheath. The electrons formed during the ionization can also gain energy within the sheath which can be seen as a multiplication of the initial secondary electron [34]. The electron yield is also strongly material dependent, and therefore, as shown by Depla et al. [28], the steepness of the I-V characteristic depends on the ion induced electron yield of the target material. As the steepness of the I$\mathrm{V}$ characteristic increases with increasing electron yield, one can therefore expect a higher peak current. On the other hand, the discharge current will decrease due to the momentum transfer as the local density of potential charge carriers will decrease. The momentum transfer can be estimated on the average energy of the sputtered atoms, and the target sputter yield. Based on the energy transfer function $\Lambda$ (see Equation 2), the average momentum transferred to the argon atoms can be calculated. For materials with a higher sputter yield, this transfer will occur 

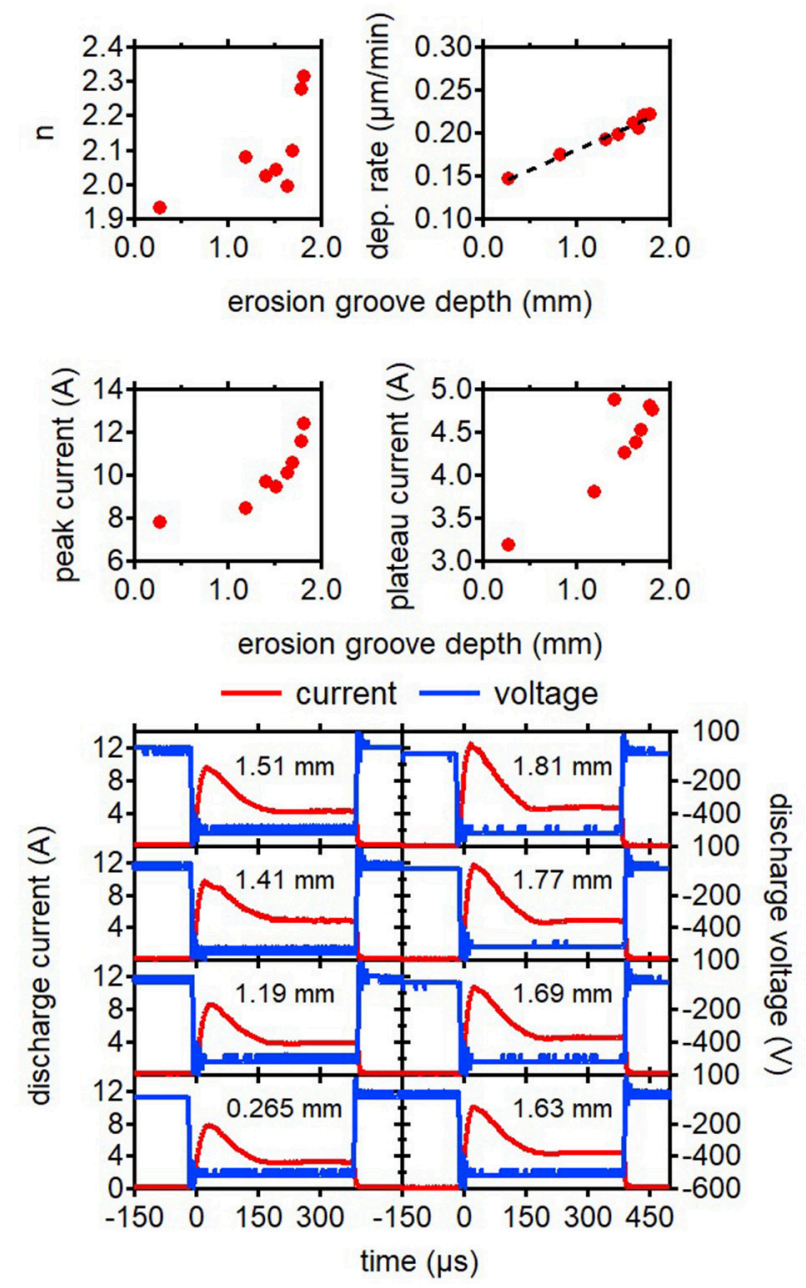

FIGURE 2 | The current and voltage pulse measured for Mg for different erosion groove depths. The peak current and the plateau current as a function of the erosion depth is shown in the top panels. The left top panel shows the slope of the I-V characteristic. The latter was determined by fitting the empirical function $I=k V^{n}$ to the experimental data. Correlation coefficients larger than 0.95 were obtained for all fits. To avoid any influence of target contamination only experiments with an average discharge power above $75 \mathrm{~W}$ were used. The right top panel shows the measured deposition rate as a function of the erosion groove depth. The argon pressure was fixed at $1.8 \mathrm{~Pa}$ for all shown results. For the deposition experiments, a $500 \mathrm{~V}$ rectangular pulse was applied for $400 \mu \mathrm{s}$. The duty cycle was set equal to $10 \%$.

more frequently. The above reasoning leads to the following test parameter,

$$
p_{\text {test }, 1}=\frac{Y \sqrt{2 \Lambda E_{\text {avg }} m_{M}}}{\gamma_{\text {ISEE }}}
$$

where $\mathrm{Y}$ is the sputter yield of the target material, $\mathrm{E}_{\mathrm{avg}}$ the average energy of the sputtered atoms, $\mathrm{m}_{\mathrm{M}}$ the atomic mass of the target material, and $\gamma_{\text {ISEE }}$ the ion induced electron yield. The energy transfer function $\Lambda$ equals

$$
\Lambda=\frac{4 m_{A r} m_{M}}{\left(m_{A r}+m_{M}\right)^{2}}
$$

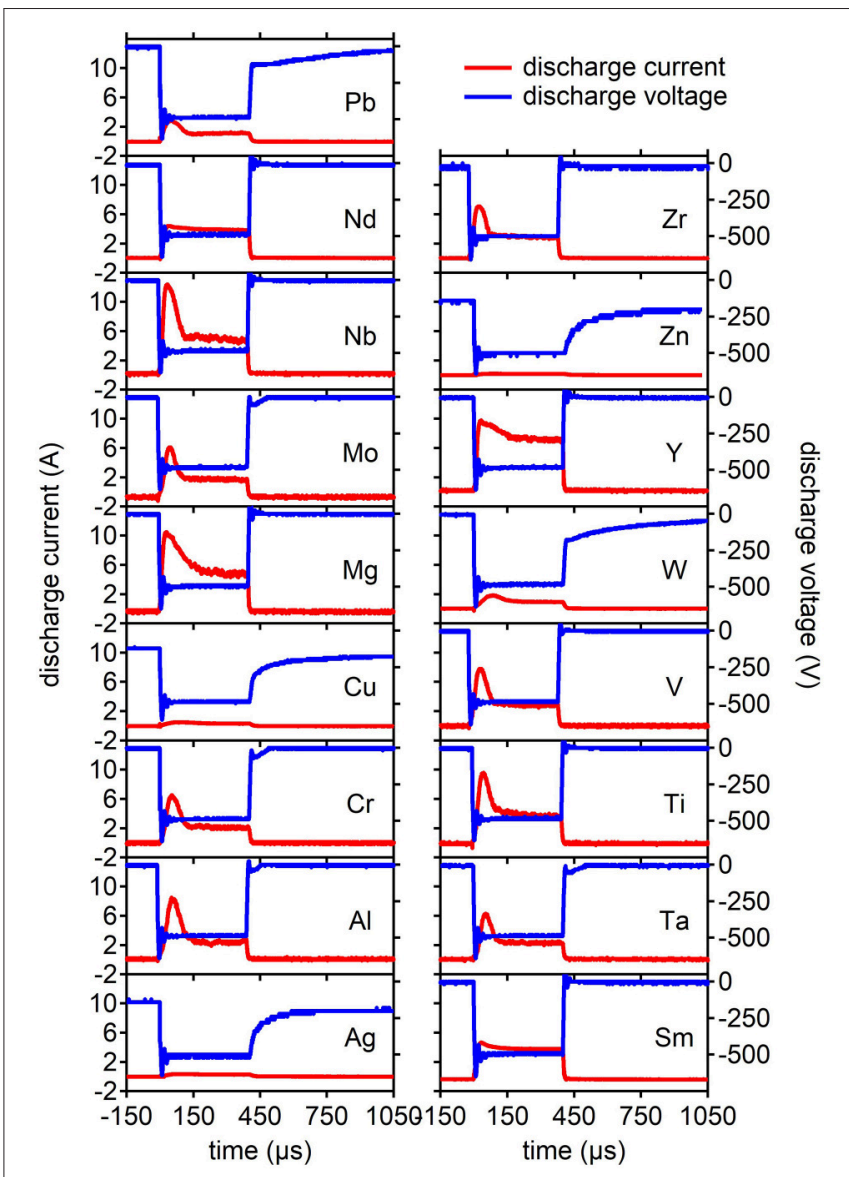

FIGURE 3 | The current and voltage pulse measured for 17 different metals. The argon pressure was fixed at 1.8 Pa. A $500 \mathrm{~V}$ rectangular pulse was applied for $400 \mu \mathrm{s}$. The duty cycle was set equal to $10 \%$.

where $m_{A r}$ the atomic mass of argon. The sputter yield of the target material can be calculated based on the approach published before by our research group [35], i.e. the ion energy is set equal to 0.75 times the average discharge voltage in the pulse, and the sputter yield is corrected for the contribution of high energetic neutrals. The average energy of the sputtered atoms was calculated based on the simplified equation proposed by Eckstein [36],

$$
E_{\text {avg }}=2 U_{s} \ln \left[\frac{E_{\text {max }}}{U_{s}}\right]
$$

where $U_{s}$ is the surface binding energy, and $E_{\max }$ the maximum energy of the sputtered atoms. The latter is approached in the paper by Eckstein as $\Lambda \mathrm{E}_{\mathrm{ion}}$, with $\mathrm{E}_{\mathrm{ion}}$ the ion energy. As shown by Eisenmenger-Sittner et al. [37] a better approach for normal incidence impact of the ion is $f \Lambda \mathrm{E}_{\text {ion }}$ with $\mathrm{f}$ equal to 0.4 . The ion induced electron yield is calculated based on the equation presented in Depla et al. [28]. The above reasoning is not completely correct as one needs to account for the number of collisions that occurs close to the target. Collisions between the sputtered atoms and the argon atoms that take place far from the target will not influence the discharge properties. As discussed 


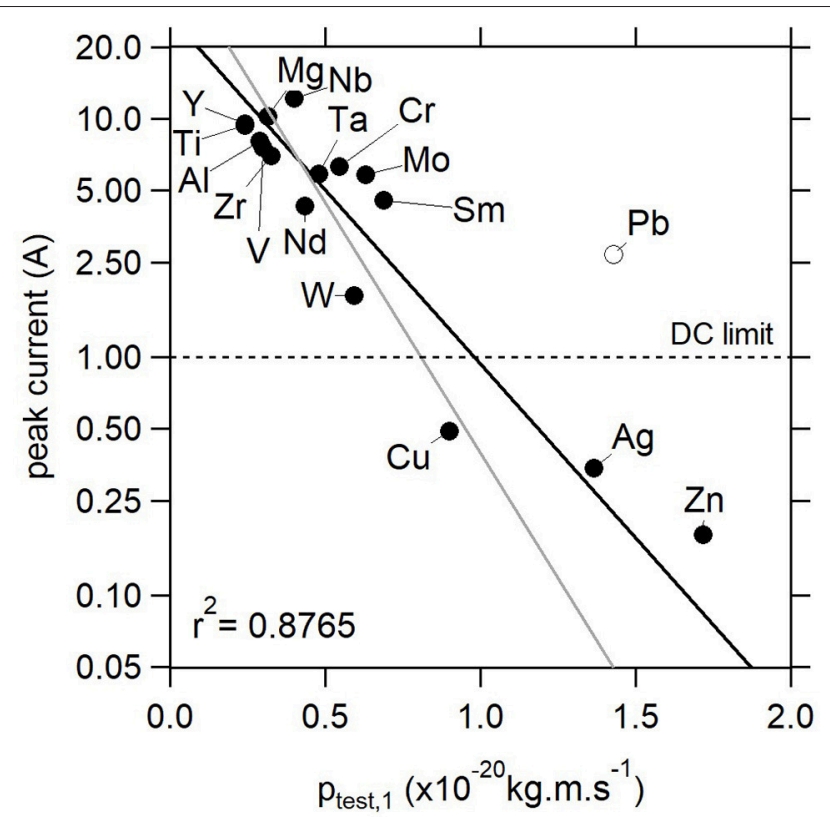

FIGURE 4 | he natural logarithm of the peak current as function of the total momentum transfer divided by the ion induced yield of the target material. The definition of $p_{\text {test }, 1}$ is given by Equation (4). The line is a fit through the data points, excluding the value of $\mathrm{Pb}$ (open marker). The gray line is a linear fit through the data, excluding the values of $\mathrm{Ag}, \mathrm{Cu}, \mathrm{Pb}$, and $\mathrm{Zn}$. The horizontal striped line is the peak power density limit for DCMS as defined by Gudmundsson et al. [31].

in section 2 the energy transferred per sputtered atom in a small volume above the target can be simulated. This leads to a better description of the test parameter as

$$
p_{\text {test }, 1}=\frac{Y \sqrt{2 E_{\text {trans }} m_{M}}}{\gamma_{\text {ISEE }}}
$$

As the experimental pressure is relatively high, the number of collisions that occur in the volume above the target is rather high, i.e. on average approximately 15 collisions. Therefore, the first approach overestimates the transferred momentum only by a factor of 2. Moreover, there is a linear correlation between the momentum transfer calculated with the two methods. Figure 4 shows the correlation between the calculated value for $\mathrm{p}_{\text {test, } 1}$ (see Equation 4), and the (natural) logarithm of the measured peak current. A strong significant correlation is found (correlation coefficient $r^{2}=0.7416$ for 17 data points, degree of confidence 99.9995\%). One element, i.e. $\mathrm{Pb}$, deviates from the fitted line (based on studentized residual analysis with a significance level of 0.05).

The much larger cross section for electron impact ionization (see further) can probably explain this behavior. The return probability toward the cathode will be higher for materials with a higher cross section for electron impact ionization. As the self-sputtering yield of $\mathrm{Pb}$ is lower than the argon based sputter yield, the effective sputter yield of $\mathrm{Pb}$ will be lower, or stated differently a lower value of $\mathrm{p}_{\text {test, } 1}$ can be expected. If

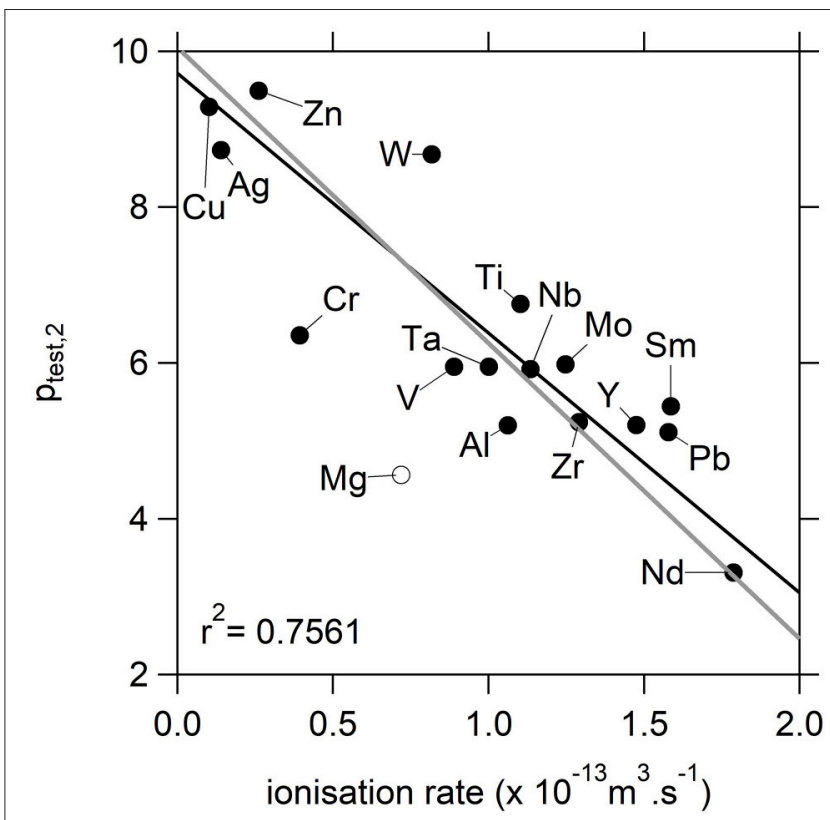

FIGURE 5 | The ratio between the average current measured in the plateau, and in the peak, normalized with the electron yield defines the test parameter 2 (see also Equation 4). This parameter shows a linear correlation with the ionization rate. The latter is calculated according the Deutsch-Mark formalism. The linear fit (see black line), and the presented correlation coefficient are calculated without the data for $\mathrm{Mg}$ (open marker). The gray line is the linear fit excluding the datapoints for $\mathrm{Ag}, \mathrm{Cu}, \mathrm{Mg}$, and $\mathrm{Zn}$.

the $\mathrm{Pb}$ data point is considered as an outlier, the correlation coefficient even increases to $r^{2}=0.8765$ (16 data points, degree of confidence is practically $100 \%$ ). One could argue that the three materials with a low peak current $(\mathrm{Ag}, \mathrm{Cu}$, and $\mathrm{Zn}$ ) have a strong impact on the linear correlation. However, even when these three elements are dropped from the analysis, the correlation is still statistically significant $\left(r^{2}=0.4425\right.$ for 13 data points, degree of confidence $99.345 \%$ ), and the fitted line (indicated in gray in Figure 4) hardly changes. For these three elements the resulting peak current is low, and a DC like discharge current density is observed. Rossnagel [38] has studied gas rarefaction during DCMS, and used a similar argumentation that leads to Equation (1). Further, in a study on I-PVD by the same author [39], the effect of gas density reduction on the ionization probability was already discussed. It is interesting to notice that the correlation between the peak current and the test parameter holds for both the HPPMS and the DCMS like conditions. Hence, the result shown in Figure 5 allows to significantly conclude that the sputter wind contribution to gas rarefaction is an important mechanism. This seems to be in contrast to the conclusion made by Huo et al. [33] that ionization losses is the dominant mechanism for gas rarefaction. This latter conclusion is based on modeling of the HiPIMS current waveform solely recorded for $\mathrm{Al}$ under identical conditions as presented in the current paper, i.e. $400 \mu$ s long pulses at $1.8 \mathrm{~Pa}$ argon pressure for a two inch diameter magnetron. From Figure 4 it is clear that in the case of $\mathrm{Al}$, the sputter wind contribution is rather small as 
compared to other metals which agrees with the conclusion by Huo et al. [33]. However, Figure 4 also shows that the conclusion cannot be generalized. Moreover, it is clearly necessary to analyze sufficient materials. Based on a seven element study ( $\mathrm{Al}, \mathrm{C}$, $\mathrm{Cr}, \mathrm{Cu}, \mathrm{Nb}, \mathrm{Ti}$, and $\mathrm{W}$ ) Anders et al. [22] conclude "The very large differences between materials cannot be ascribed to the different sputter yields but they indicate that generation and trapping of secondary electrons play a major role for currentvoltage-time characteristics." When a similar plot of the peak current as Figure 4 is made but now as a function of the sputter yield, a significant correlation is found $\left(r^{2}=0.5795\right.$, for 17 elements, degree of confidence $99.981 \%$ ). When the plot is however restricted to the same six elements as in the study of Anders et al. no significant correlation is found. Hence, within their experimental framework, the conclusion of Anders et al. is correct according to our study, but clearly when the dataset is expanded, another conclusion can be drawn.

\subsection{Plateau Current}

The peak is followed by a stabilization of the discharge current. The constant current in this regime is referred to as the plateau current. According to $\mathrm{Wu}$ et al. [21], the current waveform can be understood as follows. Before the maximum the argon ions are already replaced by metal ions, and the secondary electron yield decreases because the metal ions contribute less to the target secondary electron emission. When equilibrium is reached, the plasma is a mixture of metal and argon gas ions. When no highly charged metal ions are produced, the discharge current will stabilize, and the waveform will show a plateau until the end of the pulse. Again a simple conceptual calculation can be performed to test this hypothesis. As the current decrease is the result of the replacement of argon by metal ions, the relative current decrease should scale with the ionization rate of the metal atoms. Also, the magnitude of the current decrease will depend on the steepness of the I-V characteristic, i.e. the sharper the I-V characteristic, the stronger the effect. As mentioned before, the sharpness of the I-V characteristic scales almost linearly with the electron yield. As such the following test parameter is derived,

$$
p_{\text {test }, 2}=\frac{I_{\text {avg,plateau }}}{I_{\text {avg,peak }} \gamma_{\text {ISEE }}}
$$

The ionization rate can be calculated from the cross section for electron impact ionization, and the electron energy distribution. The latter is assumed to be Maxwellian with an electron temperature of $6 \mathrm{eV}$. This approximation is also used in advanced models for high power impulse magnetron sputtering (HiPIMS) $[27,40,41]$. The exact electron temperature has however little impact on our analysis. The cross section for electron impact ionization was calculated according the Deutsch-Mark semiclassical formalism [42-45]. The input data for this formalism, such as the ionization energy in the (nl) subshell, and the radius of maximum radial density of the atomic subshell characterized by the quantum numbers $\mathrm{n}$ and $\mathrm{l}$, were taken, as suggested in the papers by Deutsch et al., from Desclaux [46]. Figure 5 shows the test parameter $\mathrm{p}_{\text {test }, 2}$ as a function of the metal ionization rate. A linear correlation is found which confirms the above reasoning. When the $\mathrm{DC}$ like results $(\mathrm{Ag}, \mathrm{Cu}$, and $\mathrm{Zn}$ ) are removed from the analysis (see gray line) the relation correlation is hardly affected.

Again, one outlier, i.e. magnesium, is observed (based on a studentized residual analysis with a significance level 0.05). This is not surprising as the opposite reasoning as related to Figure 4 can be made. In Figure 4, Pb was observed to deviate from the found correlation. It was argued that the large cross section for impact ionization is probably the cause. In the present case, the replacement of argon by magnesium will be small because the momentum transfer between magnesium and argon is not efficient. This also agrees with the fact that this test parameter is almost constant for $\mathrm{Mg}$, irrespective of the steepness of the I-V characteristic. Indeed, both the peak and the plateau current increase with the erosion groove depth (see Figure 2). As discussed before, the deposition rate for $\mathrm{Mg}$ scales linearly with the erosion depth. So despite more $\mathrm{Mg}$ atoms are sputtered, the effect on the decrease of the plateau is minimal because the sputtered $\mathrm{Mg}$ atoms do not replace the argon atoms, and only a limited impact of gas rarefaction is observed.

\section{CONCLUSION}

Based on two simple conceptually derived test parameters, the influence of the target material on $400 \mu$ s long current waveforms during HPPMS can be understood. The peak current is defined by gas rarefaction which seems to be dominated by the sputter wind contribution. The plateau current noticed after the peak correlates to the ionization rate of the metal. As this study summarizes data of seventeen different metals, the correlations allow to predict the discharge current waveform of other less studied materials.

\section{AUTHOR CONTRIBUTIONS}

The experimental work has been performed by FM. The development of the two test parameters was performed by FM and DD. DD has written the paper, and most calculations were performed by DD. SK has improved the text, and has suggested additional experiments ( $\mathrm{I}-\mathrm{V}$ characteristics) to improve the quality of the paper.

\section{FUNDING}

Funding body : "Fonds voor wetenschappelijk onderzoek," award number G018514N.

\section{ACKNOWLEDGMENTS}

The authors wish to acknowledge the financial support of the FWO-Flanders (project BIANCO). FM would also acknowledge the university of Mons for accepting his joint Ph.D. application. SK is research associate of the Fund for Scientific Research (FNRS, Belgium). 


\section{REFERENCES}

1. Kouznetsov V, Macak K, Schneider JM, Helmersson U, Petrov I. A novel pulsed magnetron sputter technique utilizing very high target power densities. Surf Coat Technol. (1999) 122:290-3. doi: 10.1016/S0257-8972(99)00292-3

2. Ehiasarian AP, Hovsepian PE, Hultman L, Helmersson U. Comparison of microstructure and mechanical properties of chromium nitride-based coatings deposited by high power impulse magnetron sputtering and by the combined steered cathodic arc/unbalanced magnetron technique. Thin Solid Films (2004) 457:270-7. doi: 10.1016/j.tsf.2003.11.113

3. Ehiasarian AP, Munz WD, Hultman L, Helmersson U, Petrov I. High power pulsed magnetron sputtered CrNx films. Surf Coat Technol. (2003) 163:26772. doi: 10.1016/S0257-8972(02)00479-6

4. Hovsepian PE, Ehiasarian AP, Braun R, Walker J, Du H. Novel CrAlYN/CrN nanoscale multilayer PVD coatings produced by the combined High Power Impulse Magnetron Sputtering/Unbalanced Magnetron Sputtering technique for environmental protection of gamma-TiAl alloys. Surf Coat Technol. (2010) 204:2702-8. doi: 10.1016/j.surfcoat.2010.02.021

5. Sittinger V, Ruske F, Werner W, Jacobs C, Szyszka B, Christie DJ. High power pulsed magnetron sputtering of transparent conducting oxides. Thin Solid Films (2008) 516:5847-59. doi: 10.1016/j.tsf.2007.10.031

6. Vergohl M, Werner O, Bruns S. New developments in magnetron sputter processes for precision optics. In: Kaiser N, Lequime M, Macleod HA, editors. Proceedings of the Society of Photo-Optical Instrumentation Engineers (SPIE). Vol. 7101. Bellingham, WA: SPIE- Int. Soc. Optical Engineering (2008). p. 71010B. doi: 10.1117/12.797190

7. West GT, Kelly PJ, Bradley JW. A comparison of thin silver films grown onto zinc oxide via conventional magnetron sputtering and HiPIMS deposition. IEEE Trans. Plasma Sci. (2010) 38:3057-61. doi: 10.1109/TPS.2010.2066580

8. Cemin F, Lundin D, Cammilleri D, Maroutian T, Lecoeur P, Minea T. Low electrical resistivity in thin and ultrathin copper layers grown by high power impulse magnetron sputtering. J Vacuum Sci Technol A (2016) 34:051506. doi: 10.1116/1.4959555

9. Mayes ELH, Murdoch BJ, Bilek MMM, McKenzie DR, McCulloch DG, Partridge JG. Co-deposition of band-gap tuned $\mathrm{Zn1-xMgxO}$ using high impulse power- and dc-magnetron sputtering. J Phys D Appl Phys. (2015) 48:135301. doi: 10.1088/0022-3727/48/13/135301

10. Meskinis S, Gudaitis R, Vasiliauskas A, Ciegis A, Slapikas K, Tamulevicius T, et al. Piezoresistive properties of diamond like carbon films containing copper. Diamond Relat Mater. (2015) 60:20-25. doi: 10.1016/j.diamond.2015.10.007

11. Kment S, Hubicka Z, Krysa J, Olejnicek J, Cada M, Gregora I, et al. High-power pulsed plasma deposition of hematite photoanode for PEC water splitting. Catal Today (2014) 230:8-14. doi: 10.1016/j.cattod.2013.11.045

12. Ma CY, Briois P, Bohlmark J, Lapostolle F, Billard A. $\mathrm{La}_{9.33} \mathrm{Si}_{6} \mathrm{O}_{26}$ electrolyte thin films for IT-SOFC application deposited by a HIPIMS/DC hybrid magnetron sputtering process. Ionics (2008) 14:471-6. doi: 10.1007/s11581-008-0239-7

13. Aiempanakit M, Helmersson U, Aijaz A, Larsson P, Magnusson R, Jensen $J$, et al. Effect of peak power in reactive high power impulse magnetron sputtering of titanium dioxide. Surf Coat Technol. (2011) 205:4828-31. doi: 10.1016/j.surfcoat.2011.04.071

14. Broitman E, Hultman L. Adhesion improvement of carbon-based coatings through a high ionization deposition technique. In: Bilbao L, Minotti F, Kelly H, editors. Journal of Physics Conference Series, vol. 370. Bristol: IOP Pubishing LTD (2012). p. 012009. doi: 10.1088/1742-6596/370/1/012009

15. Paulitsch J, Maringer C, Mayrhofer PH. Low friction CrNMPP/TiNDCMS multilayer coatings. Tribol Lett. (2012) 46:87-93. doi: 10.1007/s11249-012-9922-y

16. Kusiak-Nejman E, Morawski AW, Ehiasarian AP, Pulgarin C, Baghriche O, Mielczarski E, et al. E. coli inactivation by high-power impulse magnetron sputtered (HIPIMS) Cu surfaces. J Phys Chem C (2011) 115:21113-9. doi: 10.1021/jp204503y

17. Alami J, Persson POA, Music D, Gudmundsson JT, Bohmark J, Helmersson U. Ion-assisted physical vapor deposition for enhanced film properties on nonflat surfaces. J Vacuum Sci Technol A (2005) 23:278-80. doi: 10.1116/1.1861049

18. Sarakinos K, Alami J, Konstantinidis S. High power pulsed magnetron sputtering: a review on scientific and engineering state of the art. Surf Coat Technol. (2010) 204:1661-84. doi: 10.1016/j.surfcoat.2009.11.013
19. Helmersson U, Lattemann M, Bohlmark J, Ehiasarian AP, Gudmundsson JT. Ionized physical vapor deposition (IPVD): a review of technology and applications. Thin Solid Films (2006) 513:1-24. doi: 10.1016/j.tsf.2006.03.033

20. Christie DJ. Target material pathways model for high power pulsed magnetron sputtering. J Vacuum Sci Technol A (2005) 23:330-5. doi: 10.1116/1.1865133

21. Wu Z, Xiao S, Ma Z, Cui S, Ji S, Tian X, et al. Discharge current modes of high power impulse magnetron sputtering. AIP Adv. (2015) 5:097178. doi: 10.1063/1.4932135

22. Anders A, Andersson J, Ehiasarian A. High power impulse magnetron sputtering: current-voltage-time characteristics indicate the onset of sustained self-sputtering. J Appl Phys. (2007) 102:113303. doi: 10.1063/1.2817812

23. Van Steenberge S, Leroy WP, Hubin A, Depla D. Momentum transfer driven textural changes of $\mathrm{CeO}_{2}$ thin films. Appl Phys Lett. (2014) 105:111602. doi: 10.1063/1.4895785

24. Moens F, Kalvas T, Van Steenberge S, Depla D. Effect of space charge on the negative oxygen flux during reactive sputtering. J Phys D Appl Phys. (2017) 50:115201. doi: 10.1088/1361-6463/aa5ab6

25. Van Aeken K, Mahieu S, Depla D. The metal flux from a rotating cylindrical magnetron: a Monte Carlo simulation. J Phys D Appl Phys. (2008) 41:205307. doi: 10.1088/0022-3727/41/20/205307

26. Depla D, Leroy WP. Magnetron sputter deposition as visualized by Monte Carlo modeling. Thin Solid Films (2012) 520:6337-54. doi: 10.1016/j.tsf.2012.06.032

27. Raadu MA, Axnas I, Gudmundsson JT, Huo C, Brenning N. An ionization region model for high-power impulse magnetron sputtering discharges. Plasma Sources Sci Technol. (2011) 20:065007. doi: 10.1088/0963-0252/20/6/065007

28. Depla D, Mahieu S, De Gryse R. Magnetron sputter deposition: linking discharge voltage with target properties. Thin Solid Films (2009) 517:2825-39. doi: 10.1016/j.tsf.2008.11.108

29. Capek J, Hala M, Zabeida O, Klemberg-Sapieha JE, Martinu L. Steady state discharge optimization in high-power impulse magnetron sputtering through the control of the magnetic field. J Appl Phys. (2012) 111:023301. doi: $10.1063 / 1.3673871$

30. Capek J, Hala M, Zabeida O, Klemberg-Sapieha JE, Martinu L. Deposition rate enhancement in HiPIMS without compromising the ionized fraction of the deposition flux. J Phys D Appl Phys. (2013) 46:205205. doi: 10.1088/00223727/46/20/205205

31. Gudmundsson JT, Brenning N, Lundin D, Helmersson U. High power impulse magnetron sputtering discharge. J Vacuum Sci Technol A (2012) 30:030801. doi: $10.1116 / 1.3691832$

32. Britun N, Minea T, Konstantinidis S, Snyders R. Plasma diagnostics for understanding the plasma-surface interaction in HiPIMS discharges: a review. J Phys D Appl Phys. (2014) 47:224001. doi: 10.1088/0022-3727/47/22/224001

33. Huo CQ, Raadu MA, Lundin D, Gudmundsson JT, Anders A, Brenning $\mathrm{N}$. Gas rarefaction and the time evolution of long high-power impulse magnetron sputtering pulses. Plasma Sources Sci Technol. (2012) 21:045004. doi: 10.1088/0963-0252/21/4/045004

34. Buyle G. Simplified Model for the d.c. Planar Magnetron Discharge [Thesis]. Ghent University (2005).

35. Depla D. On the effective sputter yield during magnetron sputter deposition. Nucl Instrum Methods Phys Res B Beam Interact Mater Atoms (2014) 328:65-9. doi: 10.1016/j.nimb.2014.03.001

36. Eckstein W. Energy distributions of sputtered particles. Nucl Instrum Methods Phys Res B Beam Interact Mater Atoms (1987) 18:344-8. doi: 10.1016/S0168-583X(86)80056-8

37. Eisenmenger-Sittner C, Beyerknecht R, Bergauer A, Bauer W, Betz G. Angular-distribution of sputtered neutrals in a post magnetron geometry measurement and Monte-Carlo simulation. J Vacuum Sci Technol Vacuum Surf Films (1995) 13:2435-43. doi: 10.1116/1.579485

38. Rossnagel SM. Gas-density reduction effects in magnetrons. J Vacuum Sci Technol Vacuum Surf Films (1988) 6:19-24. doi: 10.1116/1.574988

39. Rossnagel SM. Interaction between gas rarefaction and metal ionization in ionized physical vapor deposition. J Vacuum Sci Technol B (1998) 16:3008-12. doi: $10.1116 / 1.590333$

40. Brenning N, Axnas I, Raadu MA, Lundin D, Helmerson U. A bulk plasma model for $\mathrm{dc}$ and HiPIMS magnetrons. Plasma 
Sources Sci Technol. (2008) 17:045009. doi: 10.1088/0963-0252/17/4/ 045009

41. Gudmundsson JT, Lundin D, Brenning N, Raadu MA, Huo C, Minea TM. An ionization region model of the reactive $\mathrm{Ar} / \mathrm{O}_{2}$ high power impulse magnetron sputtering discharge. Plasma Sources Sci Technol. (2016) 25:065004. doi: 10. 1088/0963-0252/25/6/065004

42. Deutsch H, Becker K, Matt S, Mark TD. Theoretical determination of absolute electron-impact ionization cross sections of molecules. Int J Mass Spectr. (2000) 197:37-69. doi: 10.1016/S1387-3806(99)00257-2

43. Deutsch H, Scheier P, Matt-Leubner S, Becker K, Mark TD. A detailed comparison of calculated and measured electron-impact ionization cross sections of atoms using the Deutsch-Mark (DM) formalism. Int J Mass Spectr. (2005) 246:113. doi: 10.1016/j.ijms.2005.08.012

44. Deutsch H, Becker K, Mark TD. Calculated absolute cross-sections for the electron-impact ionization of atoms with atomic numbers between 20 and 56 using the Deutsch-Mark (DM) formalism. Int J Mass Spectr. (2008) 271:58-62. doi: 10.1016/j.ijms.2007.10.001

45. Deutsch H, Becker K, Probst M, Mark TD. The semiempirical DeutschMark formalism: a versatile approach for the calculation of electron-impact ionization cross sections of atoms, molecules, ions, and clusters. In: Arimondo E, Berman PR, Lin CC, editors. Advances In Atomic Molecular and Optical Physics, vol. 57 (San Diego, CA: Elsevier Acadamic Press) (2009). p. 87-155.

46. Desclaux JP. Relativistic Dirac-Fock expectation values for atoms with $\mathrm{Z}=1$ to $\mathrm{Z}=120$. Atom Data Nucl Data Tables (1973) 12:311-406. doi: 10.1016/0092-640X(73) 90020-X

Conflict of Interest Statement: The authors declare that the research was conducted in the absence of any commercial or financial relationships that could be construed as a potential conflict of interest.

Copyright (c) 2017 Moens, Konstantinidis and Depla. This is an open-access article distributed under the terms of the Creative Commons Attribution License (CC BY). The use, distribution or reproduction in other forums is permitted, provided the original author(s) or licensor are credited and that the original publication in this journal is cited, in accordance with accepted academic practice. No use, distribution or reproduction is permitted which does not comply with these terms. 